* Artigo Original

\title{
Cuidar em Contexto de Diversidade Cultural: Representações e Vivências do Corpo em Diferentes Culturas
}

\author{
Maria Nunes \\ Escola Superior de Enfermagem de Lisboa - ESEL, Lisboa \\ mariasaraiva@yahoo.com
}

\author{
Natália Ramos \\ Departamento de Ciências Sociais e de Gestão, Universidade Aberta, CEMRI, Lisboa \\ natpramos@hotmail.com
}

DOI: $10.3395 /$ reciis.v5i4.559pt

\begin{abstract}
Resumo
As mudanças sociais resultantes da livre circulação de pessoas acarretam uma grande diversidade cultural de religiões e etnias, formas de estar e de viver que impõem necessidades de se redefinirem novas prioridades nos cuidados de saúde. Em Portugal, país multicultural por excelência assiste-se já à necessidade de apoiar, na saúde e na doença, pessoas oriundas de outros países, de diferentes raças, credos e culturas. A nossa escolha recaiu em pessoas doentes e suas famílias de cultura muçulmana e hindu uma vez que as encontramos já, no nosso dia a dia em situação de grande sofrimento, essencialmente preocupadas com a forma como cuidávamos dos seus corpos doentes dando pouca ou nenhuma importância às questões relacionadas com os princípios religiosos e culturais. Realizamos um estudo de cariz etnográfico que nos permitiu realizar a nossa tese de Doutoramento. Da análise dos resultados salientamos: há diferenças na forma como cada cultura concebe a vida no seu dia a dia, no entanto, em situação de doença, as opiniões são muito similares no que diz respeito aos sentimentos vividos no corpo e a forma de os ultrapassar. Assim o Corpo Doente é vivido em ambas as culturas com maior numero de asserções como "Corpo Público" e "Corpo Desobediente" e os aspectos relacionados com a "Privacidade".
\end{abstract}

Palavras-chave: Cuidados de Saúde; Multiculturalidade; Islamismo; Hinduísmo; Corpo doente

\section{I ntrodução}

A existência de países ou cidades multiculturais tem origem, principalmente, nos fenômenos migratórios que durante o século passado se verificaram num fluxo sem precedentes. Vivemos, sem dúvida, numa sociedade multicultural e embora os fluxos migratórios sejam conhecidos há muitos séculos, foi nas últimas décadas que se tem tomado consciência desta realidade histórica quer pelas crescentes migrações em todo o mundo quer pela presença de minorias culturais que muito influenciam os países para onde se deslocam.

A busca de uma melhoria nas condições de vida das famílias, a necessidade de novos horizontes, fundamentalmente relacionados com aspectos econômicos, culturais e intelectuais são os motivos pelos quais as pessoas tendem a abandonar os seus países de origem, integrando-se noutras sociedades e noutras culturas muitas vezes de maneira traumática (MAYOL, 2003).

A percepção de que vivemos num mundo diferente, multicultural, composto por vários "diferentes" ocupando o mesmo espaço ou espaço próximo é parte constitutiva de um mundo contemporâneo, um mundo onde para alguns autores é questionado o conceito de cultura em que os próprios tempo e espaço foram desencaixados (GIDDENS, 2000) e comprimidos ao extremo das suas possibilidades (HARVEY, 2003). De fato, o conceito tradicional alterou-se substancialmente pois pode dizer-se que todas as sociedades e todos os países são compostos por uma multiplicidade de culturas que coabitam no mesmo espaço.

As sociedades, hoje, incluem entre os seus membros diferentes sistemas culturais, baseados em diferentes etnias, grupos religiosos e subculturas que levam à constituição de formas de expressão e meios de vida profundamente diferentes, mas que compartilham alguns sistemas de significados e rituais.

Somos tentados a definir a nossa identidade através daquilo que nos pertence. $O$ desafio que hoje se 
levanta implica uma mudança de perspectiva: o que somos depende do cruzamento, não daquilo que nos pertence mas daquilo a que pertencemos (AUGÉ, 1994).

A Organização Internacional para as Migrações (OIM) em 2009 refere que cerca de duzentos e catorze milhões de pessoas vivem fora dos seus países; representam 3,1\% da população global, as mulheres representam $49 \%$ destes migrantes e cerca de vinte a trinta milhões são imigrantes ilegais ou refugiados.

Portugal foi um país tradicionalmente relacionado com a emigração especialmente conotada com as características estruturais e culturais da sociedade portuguesa pela sua economia, modelo de desenvolvimento e existência de comunidades portuguesas espalhadas por todo o mundo (RAMOS, 2004). Atualmente temos pessoas oriundas dos mais diversos continentes, sobretudo provenientes do Brasil, Europa de Leste e PALOP. Calcula-se que a população muçulmana em Portugal seja constituída por 30 a 35 mil pessoas, oriundas de vários países e que a população indiana ronde as 70 mil pessoas (hindus com maior expressão, católicos, muçulmanos e ismaelitas). Ambas representam, em termos migratórios, 0,5\% da população portuguesa.

Certamente que sair das suas casas para viver num país desconhecido, muitas vezes sem família, será um processo traumático pelo que se deixou para trás e em muitos casos porque, muito poucas possibilidades há de voltar a ver as suas terras num futuro próximo.

RAMOS (1993:561) refere que o processo migratório "não é simplesmente sinônimo de encontro cultural, já que implica uma adaptação social e psicológica à cultura de acolhimento, a um meio novo, desconhecido ou hostil. Esta adaptação vai depender de fatores múltiplos relacionados com aspectos específicos da aculturação".

Algumas destas mudanças poderão ser bastante positivas especialmente no que se refere à melhoria das condições socioeconômicas, à educação e saúde; outras, nem tanto, como por exemplo dificuldades de adaptação, problemas psicológicos e stress de aculturação. O migrante carrega muito frequentemente uma dupla vulnerabilidade (psicológica e social) e uma dupla exclusão (do país de origem e do país de acolhimento) (RAMOS, 2004).

Nas sociedades contemporâneas, nas quais é preciso diferenciação dos indivíduos para que se identifiquem enquanto seres humanos e enquanto membros de determinado contexto social, sobretudo diante das possibilidades postas pela globalização, o confronto entre culturas é inevitável e necessário. Assim, a diversidade cultural passa a ser um grande desafio no que diz respeito às questões relacionadas com o convívio quotidiano. Para tanto, é preciso que se reconheçam e se respeitem as diferenças próprias de cada indivíduo.

Cada sociedade busca para si aquilo de que necessita em dado momento. Assim, se determinada cultura não lhe serve, então, deverá adaptar-se ou desaparecerá (GIDDENS, 2000).

Em Portugal, o convívio cultural com a diversidade não deveria representar uma dificuldade. Temos, historicamente, uma grande mistura de culturas, cada uma com os seus costumes, valores, modos de vida e de adaptação. Mas nem sempre é isso que acontece, especialmente quando migrantes com hábitos muito diferentes dos nossos, chegam às instituições de saúde.

Com efeito, a principal estrutura institucional de prestação de cuidados de saúde é o hospital onde os diagnósticos e tratamentos são codificados, estereotipados, e não é tido em conta, ou muito pouco, as hipóteses etiológicas das famílias, a sua percepção quanto à natureza e gravidade da doença, quando sabemos que as culturas e as famílias se organizam em torno da gravidade e dos motivos que imaginam possam ter causado tais sintomas (KLEINMAM, 1980).

Aos profissionais de saúde deverá ser possível o acesso a uma formação sólida que Ihes permita desenvolver competências interculturais para compreender e gerir, na sua prática diária de cuidados, outros entendimentos sobre a vida, a saúde e a doença e outras formas de coexistir numa ética de cuidados que implique ter em conta a cultura das pessoas doentes, suas famílias e as maneiras de a interpretar no momento em que a vivem (RAMOS, 2004, 2009).

Os resultados que iremos apresentar integram-se no âmbito de uma investigação etnográfica de Doutoramento realizada em 2011 na Universidade Aberta de Lisboa, com doentes provenientes de diferentes culturas residentes na região de Lisboa, particularmente de origem muçulmana e indiana, sob a orientação da Prof. Natália Ramos.

\section{Fundamentos do I slamismo e I nduismo}

O acolhimento e a intervenção nos cuidados de saúde com os usuários/doentes de outras culturas 
exige o conhecimento da cultura dos mesmos, pelo que iremos brevemente apresentar alguns fundamentos principais do hinduismo e islamismo.

O ISLAMISMO rege-se pelo princípio da obediência, como nos salienta um responsável religioso entrevistado:

“O Islão é um código de vida em que a obediência e o respeito pelo outro são fundamentais, não é só a religião é uma religião muito pessoal. É claro que sendo o islamismo, uma religião aberta é uma religião sempre disposta a encontrar soluções... faz parte da solução e não do problema. Esta é a visão do Islão que eu tenho. Aqui em Portugal vivem sensivelmente 40 mil muçulmanos e temos essencialmente um Islão Sunita". (SHEIK MUNIR, 2008)

É uma religião que cresce consideravelmente em todo o mundo. Depois do Cristianismo, é a religião com maior número de adeptos espalhados por todos os continentes.

“ A língua árabe é a língua litúrgica ... o que não é obstáculo para ser muçulmano”. A maioria da população muçulmana do mundo é sunita - cerca de $85 \%$. Há ainda uma minoria xiita e outros grupos como os sufis mas, em Portugal, predomina a influência sunita". (Sheik Munir, 2008)

A lei religiosa islâmica Xaria é um sistema complexo que se foi desenvolvendo desde o tempo de Maomé até aos nossos dias e é encarada com toda a seriedade. Os muçulmanos orientam as suas vidas pelo conjunto de regras, valores e princípios presentes na Xaria. O Alcorão apresenta regras muito claras relativas às atividades que todo o bom muçulmano deve cumprir e que vão desde as formas de prática do culto, o que não se pode comer, o que não se deve vestir ou como devem ser distribuídos os bens numa herança. Por exemplo, ao contrário do que se possa pensar, não há somente normas ou restrições sobre comportamentos ou maneiras de vestir para as mulheres. Um homem muçulmano nunca poderá aparecer sem camisa na frente de mulheres. O Sheik ou o Íman, se não estiver a usar roupa típica como nas cerimônias religiosas, usa camisa de manga comprida. Os homens não podem usar camisa de seda nem objetos de ouro. Para todos o vestuário deve ser sóbrio e cobrir todo o corpo. Esconder ou ocultar o corpo faz parte desse universo cultural e religioso. Um dos motivos mais explícitos tem a ver com o fato do corpo humano chamar a atenção e de não se permitir o contato entre homens e mulheres antes do casamento. Espera-se que uma certa atração resulte não do aspeto físico mas sim das atitudes tidas por cada um.

Um muçulmano não poderá viver em paz e alegria se não observar os princípios contidos no que se denomina de "Pilares da Fé" e que compreendem a Unidade Divina, a Profecia, a Revelação, a Intercessão dos Anjos e a existência de uma Outra Vida; e "Pilares da Prática" que paralelamente com os Pilares da Fé se devem seguir. São eles a Shahadah, a Oração, o Jejum, a Caridade e a Peregrinação ou Hajj. Embora sejam extremamente importantes como princípio, nem todos os muçulmanos os cumprem sempre na íntegra. Alguns cumprem-nos apenas parcialmente.

A oração islâmica é um conjunto perfeito, onde o muçulmano alcança diversos benefícios, na parte espiritual, alcança paz de espírito elevando-o, na parte física, realiza um exercício diário através dos seus movimentos, beneficiando com isso o seu corpo. Logo, o muçulmano que pratica as cinco orações diárias reforça, cinco vezes ao dia, a crença sobre a qual repousa a sua fé, pois a prática da oração é um dos maiores sinais de fé, e a prova mais óbvia da gratidão a Deus pelas Suas incontáveis graças. A oração é obrigatória para homens e mulheres.

O dia santo dos muçulmanos é à sexta-feira em que, se realiza a oração coletiva (Salát' al Jumuah). Quem conduz esta oração é o Íman, pessoa conhecedora do Alcorão e dos hadiths do profeta. Os sermões de sexta feira são lições nas quais o Íman trata, semanalmente, dos problemas que possam, durante aquela semana, ter surgido na comunidade. A oração da sexta feira só é válida se for feita na Mesquita. O horário é a oração do meio dia. A oração coletiva é, certamente, um dos maiores rituais do Islão. Há uma perfeita sintonia de vozes e movimentos e um ritmo disciplinado e cadente dos corpos voltados para Meca. Homens e mulheres rezam em locais diferentes na Mesquita.

As Práticas da Oração, constituem outro aspecto importante, segundo o Sheik David Munir, relacionam-se com as práticas de limpeza e purificação antes das orações. São tão importantes que, se uma pessoa não tiver água para as realizar terá que as simular de outra maneira. Nenhuma oração será válida se a pessoa não se purifica primeiro. Quem trabalha com estas pessoas em situação de doença, deve conhecer ou pelo menos permitir a realização deste ritual que se denomina de Wudú.

Quanto ao HINDUISMO, este rege-se pela renovação contínua da vida. Iniciado há mais de quatro 
milénios, o Hinduísmo é considerado uma das religiões mais antigas do mundo. A sua definição não engloba, somente os aspectos religiosos como nos refere um responsável religioso:

" o termo hinduísmo refere-se essencialmente a uma cultura e a um modo de viver e de pensar, intimamente associados a uma religião" (Sacerdote Nitesh, 2008).

Tal como hoje a conhecemos, o hinduísmo é uma religião de forte conteúdo ritual que atribui pouca importância aos aspectos doutrinais e que se mantém unida por um sistema de castas e pelo fato de rituais essenciais como nascimento, maioridade, casamento e morte, só poderem ser celebrados por um sacerdote brâmane.

A Índia é, talvez, o único país, onde uma grande parte dos hindus vive em harmonia com uma grande parte dos muçulmanos sem obrigatoriedade de proceder a quaisquer ajustamentos significativos embora as crenças e práticas religiosas, algumas muito intransigentes, sejam difíceis de ignorar. Isto é o resultado de séculos de interação e adaptação mútuas. (Jayaram, 2008)

A influência muçulmana fez-se sentir essencialmente com a abolição de oferendas e rituais e a adoração a mais do que um Deus. Embora, em Portugal tenhamos muitos indianos, na sua grande maioria eles professam a religião hindu. Os indianos que optaram pela conversão ao islamismo, têm um comportamento, em tudo, igual ao dos outros muçulmanos, no entanto, a coexistência destas duas religiões é pacífica e há um grande respeito mútuo entre si.

A maior figura Hinduísmo moderno é Mahatma Gandhi (1869-1948), conhecido no Ocidente como chefe político, mas venerado na Índia como líder espiritual.

“Gandhi, adepto da Ahimsa (o princípio da não-violência), apregoava a importância que tinha para o Homem o exercício de um perfeito controlo sobre si mesmo. Para ele, o sistema de castas começaria a perder o sentido uma vez que o que era importante eram os princípios de igualdade e solidariedade mas, aspectos relacionados com a estratificação social, heranças e aspectos puramente baseados em fatores materiais fazem com que estas ainda se mantenham. Mais do que uma religião, o Hinduísmo caracteriza-se como uma tradição cultural, que engloba formas muito particulares de viver, de estar em sociedade e de princípios éticos e filosóficos" (Sacerdote Nitesh, 2008).

O hinduísmo é uma religião universal com uma ênfase especial na fraternidade. Acredita-se que o Homem tem natureza divina e que o objetivo de toda a atividade humana é conhecer a verdade suprema e é por isso, que alguns intelectuais, entre eles Ghandi, lamentem a presença de castas. Sobre o sistema de castas Jayaram, um estudante indiano, residente em Portugal referia-nos que "não se compreende que uma cultura que privilegia o Homem em toda a sua plenitude o divida, depois, segundo a família de onde provém. Tal não seria tão difícil de compreender se todas as pessoas fossem integradas numa casta mesmo sendo mais inferior. Mas não! Muitos (a maioria) na Índia não têm sequer casta sendo por isso, sujeitos a uma vida de pobreza e abandono em que nem sequer são prestados os cuidados de saúde mínimos. É difícil de compreender nos dias de hoje mas todo este processo é como um dogma de qualquer uma outra religião: cumpre-se e não se discute".

Uma casta é uma divisão da sociedade baseada na ocupação e linhagem familiares. Há quatro classes distintas:

Brahamanes - são a classe sacerdotal que têm o direito de estudar os Vedas, realizar rituais para si a para os outros e obrigados a cumprir os sacramentos. Estão entre os deuses e os homens. Devem ter um comportamento exemplar e levar toda a sua vida em busca do conhecimento e da preservação das tradições.

Kshatriyas - São a classe guerreira. São treinados para protegerem as pessoas, oferecerem sacrifícios aos deuses, estudam os Vedas e asseguram a justiça. Devem também abster-se dos prazeres sexuais.

Vaishyas - classe dos comerciantes e camponeses. São responsáveis por todo o comércio e por cultivar a terra, emprestar dinheiro e criar gado. São extremamente importantes na índia porque geram riqueza. Têm direito de estudar os Vedas mas não podem casar com mulheres de castas superiores.

Sudras - Classes trabalhadores de estratos mais baixos. O único dever é o de servir as outras três castas. Não estão autorizados a estudar os Vedas ou mesmo a ouvir os cânticos sagrados. Não podem comer na companhia das castas superiores e só podem casar com pessoas da sua casta. 
O sistema de castas para muitos, pode ter servido os seus propósitos em tempos antigos, mas não se encaixa nos valores e princípios dos tempos modernos onde a democracia, os direitos fundamentais, a liberdade individual a igualdade e a não descriminação são as pedras fundamentais para uma existência pacífica.

Quanto às Escrituras Sagradas os "Vedas" são as mais antigas do mundo. Esses hinos são a palavra divina e a base do hinduísmo.

São as escrituras sagradas, hindus, reveladas pelo deus Brahma. "Vedas" é uma palavra sânscrita que significa literalmente "a ciência". São textos da fase literária mais antiga de toda a literatura indo-europeia, de fundo marcadamente religioso e que abarca cerca de dois milénios (2500-500 a.C.).

Os livros que compõem os Vedas são considerados autoridade, verdades no campo de conhecimento. O conjunto destes livros é também conhecido por shartras, livros revelados que, oferecem explicações tanto a nível material como espiritual. São compostos por uma coleção de hinos sagrados de elevada inspiração poética que mais tarde se complementa com obras sobre a interpretação da palavra revelada e a prática do culto. Famílias sacerdotais passaram os textos de geração em geração, usando complicados sistemas mnemônicos para os conservar fielmente (SHATTUCK ,2009).

Ao nível dos fundamentos importantes do hinduismo, de acordo com o Sacerdote Nitesh, há que ter em conta alguns aspectos de ordem geral e de ordem simbólica muito importantes para a vida de qualquer hindu.

Para o Hinduísmo, as pessoas possuem um espírito (Atman), que é uma força perene e indestrutível. A trajetória desse espírito depende das nossas ações, pois a toda ação corresponde uma reação - Lei do Karma.

Enquanto não atingimos a libertação final - Moksha -, passamos continuamente por mortes e renascimentos. Este ciclo é denominado Roda de Samsara, da qual só saímos após atingirmos a Iluminação ou a Perfeição.

Os rituais compõem-se de dois elementos principais: Darshan, que é a meditação / contemplação da divindade, e o Puja (oferenda).

A alimentação vegetariana é um dos pontos essenciais da filosofia hindu. Isso porque é livre da impureza (morte / sangue), e como todo alimento deve ser antes oferecido aos deuses, não se poderia oferecer algo que fosse "sujo".

As preces são entoadas como cânticos no idioma sânscrito, língua "morta" que deu origem ao hindi. Essas preces recebem o nome de Mantras. Os Mantras são dirigidos a diversas divindades, ou estimulam qualidades pessoais.

O Mantra mais importante é o OM, "sílaba sagrada" que representa o próprio nome de Deus. OM é a semente de todos os Mantras e princípio da criação. Foi dele que derivou toda a matéria.

A visão hindu de vida após a morte é centrada na ideia de reencarnação. Os hindus mantêm muitas crenças distintas, mas todas são baseadas na ideia de que a vida na Terra é parte de um ciclo eterno de nascimentos, mortes e renascimentos.

O corpo é cremado, depois de devidamente limpo e adornado. Existe um crematório no cemitério do Alto de São João que responde, desde há muitos anos, a estas necessidades dos hindus que vivem em Portugal.

Dentro da sociedade indiana, os membros de uma família geralmente vivem juntos e isto inclui os avós, pais, filhos, bem como as famílias dos tios dos pais. Com uma maior mobilização para as áreas urbanas, essa estrutura avança lentamente para a da família nuclear formada por pais e filhos. Em Portugal encontramos várias modalidades de convívio familiar: encontramos a família nuclear, mas o que predomina é a família extensa em que os avós desempenham um papel fundamental na educação dos filhos e dos netos.

Há valores fundamentais relativamente à privacidade e em caso de doença ou decisões relacionadas com a saúde frequentemente, decide-se primeiro na família e só depois se recorre a ajuda externa. É esta união que faz com que, quando alguém está internado se verifique uma autêntica romaria de familiares a visitarem o mesmo doente. Em casa é também normal a família de alguém que está doente receber muitas visitas. 


\section{O Corpo - Representação e I dentidade Cultural}

$\mathrm{Na}$ atualidade, a diversidade de pessoas oriundas de outras culturas, faz com que tenhamos que repensar nas práticas de cuidados de saúde de uma forma mais coerente, coordenada e eficaz, não desligadas dos seus contextos individuais, sociais e culturais.

A cultura e o conhecimento sobre a diversidade cultural, são a chave que melhor permitirá adequar as práticas de cuidados às necessidades da sociedade contemporânea. São novos desafios que temos que enfrentar e temos que tomar consciência de que, quando se fala de transculturalidade, interculturalidade ou multiculturalidade, estamo-nos a referir não só à diversidade cultural como também à diferença e à convivência com essa mesma diferença.

Conhecemos pouco sobre os Outros, sobretudo sobre o Outro doente e o nosso etnocentrismo, uma vez que podemos estar em posição (cultural) maioritária, pode levar-nos a não valorizar convenientemente alguns aspectos identitários e comportamentais - pouco valorizados na nossa cultura - e a aumentar a dor e a lesar, seriamente, quem se entrega aos nossos cuidados. De acordo com GARCIA (1995:84) "(...) A cultura define e tipifica as doenças e dota-as de significado social e cria o seu contexto terapêutico."

Nunca é demais referir que não é possível prestarmos cuidados de saúde com qualidade sem atendermos às características culturais de ambos os intervenientes na relação - o profissional de saúde e o usuário. As competências culturais situam-se assim, como novos desafios para uma prática diária de cuidados que se procura a mais adaptada para promover a saúde e bem estar e prevenir a doença e a sofrimento. Falar do corpo como instrumento privilegiado de cuidados é muito mais do que mencionar as sensações que se têm quando cuidamos de alguém. É fazer um percurso pessoal que é mais do que utilizar as mãos para manipular, transportar, levantar, puncionar, acariciar e massajar.

O corpo, por excelência o principal objeto dos nossos cuidados, é objeto cultural e o mais privado que possuímos, sendo ao mesmo tempo aquilo que mais facilmente usamos para nos relacionarmos socialmente. Funciona como lugar de categorização social e de acordo com GOFFMAN (1988:22) "podem observar-se as marcações operadas pelo vestuário, ou pelos modos de apresentação de um corpo semi-nu, atlético ou sexual, ou a estigmatização de um corpo deficiente, deformado ou doente"

O corpo humano, para além do seu caráter biológico, é afetado pela religião, grupo familiar, cultura, classe social e cumprindo uma função ideológica - onde a aparência funciona ou não como garantia da integridade de uma pessoa, tem um forte impacto na forma como se articula no campo da representação social que segundo MOSCOVICI (1989:63) (...) "não é uma cópia nem um reflexo, uma imagem fotográfica da realidade: está em transformação com o objeto que tenta elaborar. É dinâmica e flexível e permite ao sujeito do conhecimento a possibilidade de ser ativo e criativo."

A socialização cultural não só modela a razão, o intelecto, a emoção e o afeto como também o corpo onde haverá sempre uma zona obscura e sombria, zonas caladas onde o corpo não é o corpo e onde o corpo estabelece os seus confusos e instáveis limites (NAVARRO, 2002).

O corpo tem inspirado inúmeros discursos ao longo da história, do mito aos aspectos religiosos e destes à ciência. A corporeidade foi sempre uma grande preocupação do Homem talvez porque, é quase sempre o corpo que se apresenta primeiro como significado da pessoa. De acordo com COSTA (2004:20) (...) a medida ética do interesse pelo corpo, não está no montante de cuidados a ele dedicado, mas na significação que os cuidados assumem. Se o interesse pelo corpo começa e termina nele, caímos na corpolatria, forma de ascese humanamente pobre e socialmente fútil. Se, ao contrário, o interesse toma a direção centrífuga, volta-se para a ação pessoal criativa e amplia os horizontes de interação com os outros (...). Tal reflexão está de acordo com o que referiu MARCEL MAUSS (1974) acerca da dimensão social da corporeidade; a forma como andamos, corremos, choramos, usamos e tratamos do nosso corpo exprime origens e crenças de determinada sociedade e empresta-Ihe significado.

Na realidade e de acordo com BAUDRILLARD (1995) o estatuto do corpo é um fato da cultura. A relação que o homem estabelece com o seu corpo reflete o modo como ele firma os seus vínculos sociais e estrutura a sua organização econômica. Assiste-se à conquista do corpo e à sua transformação em propriedade individual e privada, este é hiperinvestido, sobrevalorizado e ganha um valor sem precedentes na história das civilizações atuais merecendo um lugar de destaque em todos os média. De acordo com SANT'ANNA (2004:130) (...) diversos cultos ao corpo hoje em expansão, podem tanto transformar o corpo num espécie de casamata, da qual nada vaza, na qual nada penetra, e junto a qual nada germina, como podem, diferente disso, fazer do corpo um 
O uso do corpo é ao mesmo tempo individual e coletivo, social e natural, quer dizer, as pessoas manifestam-se com o seu corpo e através do seu corpo. Não é algo que se possa pressupor antecipadamente, nem mesmo é universal: o corpo é provisório, mutável e mutante (GOELLNER, 2003).

Nascemos com um corpo que, desde o nascimento, através da ação e do movimento, se adapta, transforma e assume uma corporeidade sem a qual não se pode expressar nem comunicar.

É aqui que, por vezes, aparecem as barreiras que tornam difícil o cuidado de saúde. As percepções e vivências de saúde e doença são diferentes não só porque lidamos com necessidades individuais e com pessoas de outras culturas mas, também, porque estamos numa posição em que se impõem dependências e autonomias diferentes. De acordo com RAMOS (2008:4) "(...) o encontro com a diferença cultural nos cuidados de saúde, pode levar a fortes reações emocionais ou a atitudes de rejeição dos profissionais de saúde, sobretudo quando não há um bom conhecimento sobre a cultura do doente e formação na área da interculturalidade"

A comunicação constitui um elemento integrador, que permite redimensionar as relações entre os indivíduos, entre o indivíduo e a sociedade, entre a sociedade e a cultura. Há códigos culturais e linguísticos que podem afetar a percepção da comunicação a nível dos olhares, das representações e estereótipos sobre os outros, sobre os acontecimentos e ao nível dos processos verbais e não verbais (RAMOS, 2008).

Uma comunicação culturalmente competente implica a consciência e o conhecimento sobre as formas de encarar a saúde e a doença, e a compreensão de que os fatores socioculturais têm efeitos importantes sobre os comportamentos relacionados com a saúde. Daí advém a consequente aquisição de competências que permitem ao doente fazer face ao problema que está a viver, permitindo-Ihe gerir a situação uma forma mais equilibrada.

Não ter em conta estes fatores acarreta segundo RAMOS (2004:298) várias consequências:

\begin{abstract}
"aumenta o sofrimento, a ansiedade, a insegurança e a dificuldades de adaptação à doença; origina insatisfação quanto à qualidade dos cuidados prestados e quanto ao comportamento do profissional de saúde; aumenta as dificuldades de avaliação ou de diagnóstico; diminui a adesão a comportamentos preventivos ou medidas protetoras de saúde e aumenta a possibilidade de abandono ou descuido na procura de cuidados".
\end{abstract}

Uma das primeiras dificuldades dos doentes pertencentes a outras culturas verifica-se no momento em que chegam ao hospital. Desconhecem as regras de comportamento hospitalar, os documentos necessários, a posição e direitos da família em todo o processo, as horas de visita, os hábitos alimentares condicionados pelo internamento, o vestuário necessário e toda uma variedade de dificuldades que terão que enfrentar em conjunto com a sua nova situação de sofrimento e doença. É-Ihes difícil compreender porque não podem ter à sua volta as pessoas que têm em suas casas ou vizinhança e são desprovidos de todo o conforto que as pessoas significativas lhe podem trazer pelo simples fato de Ihes fazerem companhia.

Estas visitas coletivas, são importantes, para diminuir o medo e a angústia e ajudam a reforçar os laços comunitários. É importante que as equipas de cuidados tenham em conta a diferente inserção cultural e social do doente e flexibilizem a adaptem as atitudes e a relação com a pessoa doente neste contexto (RAMOS, 2008)

O corpo e a forma como será tratado, é um dos aspectos que mais perturbam pessoas de outra cultura e religião. De uma maneira geral é o profissional de saúde que dá as diretrizes e as explicações e, frequentemente não temos em conta que em muitas culturas, tantas perguntas não são bem aceites. Alguns pacientes, não só não respondem como não pedem nenhuma clarificação sobre o assunto. Tais premissas podem levar a que as pessoas doentes podem não entender a sua condição ou não serem capazes de seguir o seu plano de tratamento comprometendo bastante o seu processo de recuperação.

Esta situação é complicada tanto para o doente como para o profissional de saúde: o primeiro não sabe explicar o que tem e o segundo não consegue descobrir o que tem o primeiro nem agir em conformidade. Em situações de doença aguda este fato pode ser perigoso. Um tradutor poderia resolver o problema mas, verifica-se que, em algumas situações o doente tem relutância em explicar a uma terceira pessoa o que se passa consigo, especialmente se os problemas que apresenta são de índole mais íntima. Este recurso nem sempre muito ficaz em todas as situações, já existe nalgumas unidades de saúde. 
Para serem desenvolvidas competências de comunicação nas relações interculturais é necessário que os profissionais de saúde reflitam sobre os seus comportamentos e atitudes e de que forma os podem adequar noutros contextos, cultivando a capacidade para aprendizagens culturais que lhes permitam analisar o mundo sob o ponto de vista de uma outra cultura.

\section{A Vida do Corpo Doente}

\section{Corpo Objeto}

O corpo doente é motivo de exploração. Examina-se, administram-se fármacos, abre-se, fecha-se como se de um ser inanimado se tratasse. Instrumento por excelência sobre o qual se prestam cuidados, é muitas vezes esquecido como corpo vivido, pertencente a um ser que tem uma vida e intimidade para além daquela imposta pela doença e pelo internamento. Há que encontrar um caminho que permita aos profissionais de saúde ir mais além do que utilizarem as mãos para manipular, transportar, suturar, puncionar entre muitas outras atividades que, muitas vezes, para terem uma ação curativa têm que magoar, provocar dor primeiro. A demonstração de respeito é um princípio ético que todos deveriam respeitar. A respeito do Corpo Objeto eis algumas afirmações mais significativas.

“Sinto-me uma coisa. Não uma pessoa mas uma coisa. É triste ver que não me posso lavar sozinho. Estou para aqui à espera que vejam o que eu tenho. Eles (médicos) chegam, conversam, decidem e já está". (Muçulmano, 30 anos)

" O meu corpo não faz parte de uma pessoa. Faz parte de um livro de doenças e de medicamentos. É igual a todos os outros que têm esta doença". (Hindu, 60 anos)

Este sentimento de impotência faz com que seja muito difícil para o doente, acreditar que algo de bom possa vir. Depois as atitudes dos profissionais de saúde, concorrem em muito para isso. Este é um aspecto que, os profissionais têm que melhorar. Presumir, por exemplo, que uma pessoa não sabe falar português não é a mesma coisa que não poder comunicar. Às vezes abusando dessa presunção, quando cuidamos de uma pessoa mais jovem, isso pode ter proporções graves. Já não é a primeira vez que o pânico se instala e que o doente incompreendido e confuso sai a correr do hospital pondo em perigo a sua vida.

Encarar o corpo como um objeto, nem sempre com má intenção, certamente, é perpetuar a despersonalização do outro e a nossa. O corpo da pessoa que está face a nós é como o nosso, está é num estatuto diferente naquele contexto. Pensando sempre como gostaríamos que nos tratassem e colocando-nos no lugar do Outro, poderemos melhorar o nosso ato de cuidar na sua verdadeira essência.

"Viraram- me do avesso como se fosse um brinquedo". (Hindu, 25 anos)

"Mal me tocam. Olham para mim como se eu fosse uma não pessoa". (Muçulmano, 30 anos)

"Quando me dão banho, a meio, vão-se embora. Deixam-me como se eu fosse um boneco". Voltam e começam tudo outra vez. Conversam, mas não é comigo".(Muçulmana, 25 anos).

A despersonalização ou objetivação do corpo conduzirá, certamente, a cuidados impessoais e muito pouco gratificantes. Além da disponibilidade mental necessária para se lidar com pessoas doentes, os profissionais de saúde devem estabelecer uma relação empática. Sem isso, nunca poderemos compreender o Outro, sobretudo o Outro doente.

Gostamos muito de dançar. A dança é um escape... uma alegria... mas só se o nosso corpo obedecer... O nosso corpo é uma arma. Temos códigos que só naquele grupo de amigas se conhecem. (Hindu, 42 anos)

Empatia é a percepção exata dos sentimentos vividos pela outra pessoa. É a experiência de, segundo DRUCKER, (1990: 539) "(...)estar na pele da outra pessoa, sem no entanto sentir ou pensar os sentimentos ou pensamentos dela. Empatia não é simpatia, em que o profissional tem pena do doente. É sim um sentimento de 'estar com' o doente."

Todos somos capazes de agir de uma maneira tolerante, generosa e compreensiva consoante o momento em que vivemos. Como todas as qualidades, também a empatia é susceptível de se desenvolver e aperfeiçoar e ROGERS (1972:107) refere que " (...) quem pratica esta forma de 
compreensão do outro, rapidamente descobre que a aquisição desta capacidade de interação, representa um enriquecimento pessoal com repercussões muito positivas na vida de ambos os intervenientes. "

As atenções dos profissionais de saúde voltam-se geralmente para o órgão doente. O hospital comporta-se como uma oficina na qual o corpo é arranjado, afinado com peças removidas ou substituídas. Aos profissionais pede-se competência para desempenhar essas funções. Como técnicos, isso não é difícil; o que é mais trabalhoso é a forma como se estabelece um diálogo entre a técnica executada e a humanidade necessária para a fazer funcionar (POLAK, 1996).

\section{Corpo Inútil}

O nosso corpo, até uma certa altura da nossa vida, desempenha, na maior parte das vezes muito satisfatoriamente, as funções, atividades e expectativas que Ihe atribuímos. Mas um dia, tudo muda! A doença rompe com a vida normal de um indivíduo, separando-o de atividades que considerava simples e perfeitamente exequíveis e impõe-lhe novas situações que nem sempre são encaradas como desafios. Uma doença é sempre violenta e traiçoeira, pela surpresa ou porque nos impõe a sua própria forma e não nos ensina a ultrapassá-la.

O doente é encarado muitas vezes como rebelde ou revoltado e classificado como "doente difícil". Frequentemente, aquela pessoa não teve tempo de se preparar para o que lhe está a acontecer, para se adaptar à doença e à perda, precisando de alguém que o escute e sirva de mediador entre ele e a sua nova situação. O apaziguamento, a adaptação é um elemento fundamental que produz resultados favoráveis na evolução do estado de saúde. A dificuldade está em ter essa capacidade de mediação. A este nível destacamos alguns testemunhos:

"Não sirvo para nada" Antigamente ainda fazia alguma coisa mas sinto-me tão cansada que nem me consigo pentear. (Hindu, 42 anos)

“A comida para nós, muçulmanos, é fundamental e eu que deveria transmitir o meu amor através dela não o posso fazer. O meu corpo não consegue! Sinto-me uma inútil" A minha vontade é desaparecer. (Muçulmana, 39 anos)

“ Tenho vergonha de não poder brincar com os meus filhos. Nem os posso sentar ao colo como costumava. Não tenho forças nem para rir. Nunca me senti tão incapaz e isso dá-me uma raiva". (Hindu, 45 anos)

"O meu marido nem me toca. O meu corpo já não o seduz". Deve ser porque ainda não consegui ter filhos. O meu corpo não serve para nada! (Hindu, 25 anos)

"O meu corpo é uma casca gasta sem nada dentro". (Hindu, 60 anos)

“Não há nada que eu possa fazer para apagar este aspecto. Se ponho pinturas ainda é pior. Pareço um fantasma. As pinturas, que ajudam toda a gente, comigo parece que ainda fazem pior. Só me faltam uns cordéis nas mãos para parecer uma marioneta". (Hindu, 42 anos)

"Nem sei para que serve o meu corpo. Só me estorva". (Muçulmano, 30 anos)

O corpo deixa de ter significado quando não pode executar as tarefas mais simples. Há fragilidades que as pessoas não aprendem a dominar. Torna-se num desconhecido a quem não nos adaptamos, mas com quem teremos que conviver. Evidentemente que podemos ajudar estas pessoas a encontrar alguns significados nas suas vidas, mas, são geralmente estes momentos que desanimam e que às vezes tornam difícil a abordagem por parte dos profissionais de saúde. Por vezes é necessário esperar por um momento mais propício para motivarmos estes doentes e aí, há que não desperdiçar o momento.

\section{Corpo Sensual}

A sensualidade ou a beleza do corpo não se fica somente pela aparência ou pela relação. Um corpo poderá ser sempre sensual segundo o tipo de abordagem. É um jogo a dois ou não, em que o profissional de saúde pode e deve ensinar a pessoa doente a olhar de outra forma para o seu corpo. É muito difícil, talvez o mais difícil de tudo mas, alguma empatia e criatividade poderão ajudar. A arte está na congruência do que se diz e do que se faz. Encarando, desde sempre a arte de cuidar, WATSON (1994:XV) afirma que,

(...) a verdadeira essência para quem cuida, como em qualquer outra arte, reside (...) 
numa imaginação criativa, num espírito sensível e numa compreensão inteligente que apoia todas as técnicas e habilidades. Sem isto, cuidar pode tornar-se altamente técnico, mas jamais poderá ser considerada como uma verdadeira arte. "

Convém notar que o nosso corpo não é uma entidade natural: ele é uma dimensão produzida pelos imperativos sociais e culturais. A nossa sensação física passa, obrigatoriamente, pelos significados e elaborações culturais que um determinado meio ambiente e social nós proporciona (MAUSS, 1968).

“Apesar desta amputação na perna, não me deixo abater. Ainda sou jovem. Tenho que lutar pelo equilíbrio da minha casa e por isso não posso deixar que o meu marido tenha falta dalguma coisa. No quarto danço muitas vezes para o meu marido". (Muçulmana, 50 anos)

Enquanto a doença não me corroer tenho que aproveitar. Arranjo-me melhor agora. Gosto de elogios! Às vezes nem parece que sou doente! Toda a gente diz". (Hindu, 25 anos)

De fato, a exibição dos corpos pode ser tanto maior quanto mais houver auto-controle. A excitação está relacionada, nesse caso, ao olhar, que também implica socialização (ELIAS, 2000; HEILBORN, 2002). A cultura é a grande responsável pela transformação de corpos sexuados em corpos socializados, inseridos em redes de significado responsáveis pela orientação sexual e escolha dos parceiros. É através de valores que se modelam e orientam os desejos - o que faz, por exemplo, não considerar, de uma maneira geral, os pacientes como possíveis objetos sexuais. E muitas vezes se estivermos atentos, podemos valorizar o que ainda fica de um corpo estropiado ou com uma aparência diferente do habitual. Por experiência, os doentes gostam muito que reparemos no que ainda podem fazer e não no que não podem fazer.

A ideia de que existe uma natureza humana, uma essência imutável, que percorrerá todas as culturas, todos os grupos sociais em relação à forma como encaram o seu próprio corpo é mais ou menos inalterável (LE BRETON, 1995).

Cada um aceita a sua imagem como deseja, seja ela imaginária ou verdadeira. Esse fato ajudará a ultrapassar as limitações impostas pela doença ou deficiência.

"Agora sou muito mais vaidoso. Num homem até pode parecer mal mas ainda olham para mim com algum desejo. Tenho uns olhos bonitos e até recebo piropos". (Muçulmano, 30 anos)

Ao cuidarmos de alguém podemos pensar noutras opções que não as exclusivamente técnicas. Podemos tentar pelo menos, estar atentos e ser criativos já que o doente, na maior parte das vezes não tem força para o fazer.

Gosto muito de roupa bonita e imaginação não me falta! O corpo anda tapado mas pode andar tapado com bom gosto não é? As pessoas até reparam mais se o corpo andar tapado. É fora do vulgar nos tempos que correm". (Hindu, 40 anos)

De fato analisando as nossas práticas, como profissionais de saúde, observamos que somos chamadas a reconstruir a nossa praxis a partir da vivência e da experiência do quotidiano, com sensibilidade e alguma criatividade, com o objetivo de uma melhor adequação dessas mesmas práticas ao serviço da comunidade e do bem estar e da saúde.

Na prática diária isto faz grande diferença porque, de uma maneira geral, a família situa-se muito na recordação de como aquela pessoa era e isso, por vezes, torna-a ainda mais dependente. Aos profissionais de saúde exige-se uma capacidade de escutar sem julgamento, criatividade e mobilização de recursos que ajudam doentes e famílias a lidarem com as situações. Mostrar verdadeiro interesse em escutar e ajudar é um conceito chave para a recuperação de uma pessoa. As equipas de saúde, multidisciplinares terão muito melhores condições de o conseguirem.

“ A doença não atrapalha muito o meu corpo... faço tudo em casa mas mesmo tudo! Por enquanto ainda não tenho limites... para nada..." (Muçulmano, 40 anos).

A pessoa doente, porque dependente, deprimida ou desfigurada, raramente se sente atraente e por isso, na nossa prática diária, só muito dificilmente se consegue que este padrão de beleza visível se mantenha.

O doente compreende e fica satisfeito quando fazemos e adaptamos as nossas práticas especialmente para ele e quando temos a preocupação em deixar o seu meio ambiente organizado 
de forma harmoniosa e confortável. Podem até ser, por vezes, práticas muito técnicas mas isso não é impeditivo para um profissional de saúde não as fazer com arte, sensibilidade e empatia.

\section{Corpo Desobediente}

A experiência de doença não seria, tão traumatizante, se a sua tradução corporal e o seu sofrimento não fossem tão evidentes. Além de doente e dorido, o corpo não obedece e isso dá à pessoa a verdadeira dimensão da sua autonomia e dependência. Aos profissionais de saúde, restará alguma originalidade para lidar com esta situação. Nem sempre é fácil procurar constantemente no Outro aquilo que é único e com subjetividade e individualidade, produzir novas visões do problema e novas soluções também. O desafio é enorme e muito compensador quando se ultrapassa. Tudo se tenta com um corpo que nem sempre está de acordo em obedecer.

“O meu corpo é tão rebelde que nem aos medicamentos obedece". (Muçulmano, 26 anos)

Na sua relação diária com as pessoas, o profissional de saúde cria um ambiente de compromisso e de confiança que como refere APPLETON (1993:899) se transforma (...) numa relação original, expressa por sentimentos fortes baseados na intuição e empatia que permite a ambos a consecução das suas aspirações, pois existe uma nesta permuta uma perspectiva humanista.

Lidar com um corpo desobediente é frustrante e difícil tanto para os profissionais de saúde como para os doentes.

"Gostava que o corpo me obedecesse como de costume ... mas ele é teimoso". (Hindu, 60 anos)

"Eu quero ir para um lado e o corpo quer ir para outro. O que mais me perturba é que sou sempre eu que perco este jogo". (Muçulmano, 30 anos)

Não podemos deixar de referir as populações migrantes pertencentes a minorias étnicas e culturais que, pelos seus hábitos de vida, habitação precária e impossibilidade de recorrerem aos serviços de saúde, são muito mais vulneráveis. Dificuldades em compreenderem a língua do país de acolhimento e completo desconhecimento dos trâmites necessários para acederem às unidades de tratamento fazem com que aspectos relativos ao desconhecimento sobre tratamentos e prevenção de doenças sejam uma ameaça e aflição.

É, igualmente, importante ter em conta que os migrantes e minorias adoptam menos medidas de saúde preventivas, recorrendo só aos médicos e hospitais em caso de emergência ou em estado avançado de doença, e que uma grande parte das doenças graves a que estão mais expostos (por exemplo, doenças infecciosas como a tuberculose, a hepatite B e C, O (HIV-SIDA) podem ser prevenidas ou tratadas (RAMOS, 1993, 2004, 2006, 2009).

“Nunca pensei que o corpo se deteriorasse tão depressa. Todos os dias noto que perco capacidades... a um ritmo alucinante". (Muçulmano, 30 anos)

O esquema corporal de um indivíduo é tido como a experiência imediata de uma unidade do corpo, percebida pelo próprio. Porém, é mais do que uma percepção. Todas as pessoas têm uma imagem pluridimensional do seu corpo que pode ser, visual, motora, auditiva ou tátil que é analisada como um todo e não separadamente (SHILDER, 1999).

Gostaria que me recordassem como eu era e não como eu sou... mas isso é difícil. Como eu sou... é o presente... o resto é passado e é muito fácil esquecer... o corpo não deixa. (Hindu, 45 anos)

Qualquer mudança que faz lembrar o que o corpo já foi e às vezes, do que fazia. A aproximação do fim da vida do corpo cria apreensão e gera na pessoa doente e em toda a família, mecanismos que visam diminuir a dor do próprio processo de adoecimento e a adopção de estratégias que permitam terminar esta vida com a maior harmonia possível.

Tanto na cultura islâmica como na hindu, a preocupação constante é com o sofrimento e com o futuro dos que ficam.

A religião, nestas duas culturas, ajuda a encaminhar o corpo para a transformação numa coisa muito mais importante do que o simples fato de sermos matéria, ou seja, a vida da alma.

“ Sinto que o meu corpo está teimosamente a terminar. Gostava que fosse depressa! Ao menos sei que me transformarei noutra coisa". (Hindu, 60 anos) 
O corpo não sente prazer nem com cheiros nem com sabores. Sinto que esta casca frágil que me envolve está prestes a partir-se e eu não tenho forma nenhuma de o impedir. (Hindu, 42 anos)

O corpo é um objeto que se constrói como identidade. Nascemos com um corpo, um esboço de imagem do mundo construído pelos pais, e sob uma influência cultural forte. Mas esse corpo construído, não corresponde ao nosso corpo concreto. Há uma profunda relação entre a imagem que temos do nosso corpo, a nossa identidade cultural e os olhares e estímulos que recebemos dos outros (ALBUQUERQUE, 2009).

A morte, por inerência, faz parte de uma vida que decorreu em determinado contexto. O problema é que por vezes, essa mesma morte, não acontece no mesmo contexto e vivência.

Nunca pensei que se sentisse tanto a morte. É no corpo que se vê. O cheiro não é o mesmo. É mau. Ponho perfumes mas ele não os aceita. (Muçulmana, 50 anos)

Já não tenho a mesma cara nem as mesmas mãos. Estou a ficar seco e a murchar. Já não sou eu! Algumas pessoas só me conhecem pela voz. Sinto que estou a terminar. (Hindu, 60 anos)

“O corpo não obedece mas ele é que manda. É como a Natureza. Se não quer não há nada a fazer". (Muçulmano, 26 anos)

"Não consigo rezar, o meu corpo não deixa. Só espero que Deus compreenda". (Muçulmana, 19 anos)

As manifestações de fé quer através de orações quer através de rituais, ajudam as pessoas a fazer esta transição mais ou menos pacificamente. Mas, muito frequentemente tal não é possível. Umas vezes pelas rotinas instituídas nos hospitais, outras vezes porque é o próprio corpo que o impede. Temos que ter a noção que como cuidadores, nem todas as orações são ditas ou mentalmente recitadas. Às vezes o próprio corpo é a oração.

\section{Corpo Público}

Uma relação, só é possível quando os seus intervenientes chegam a um consenso após a quebra da barreira do primeiro encontro. Emergem sentimentos de solidariedade e empatia e DANIEL (1991:33) chama a atenção " (...) para a demonstração de cortesia, compreensão e interesse. Tais atitudes são responsáveis por uma melhor capacidade de ajustamento à situação."

Ter a capacidade de dar prazer a alguém enquanto doente segundo MICHALIS (2002:3), "(...) permite ao cuidador criar um clima de conforto que permitirá à pessoa doente ganhar algum controle sobre o seu processo de recuperação."

A reação de cada pessoa ao anúncio e confirmação da doença é sempre única. Em situações em que há grande impacto na imagem corporal, as pessoas doentes tornam-se muito mais dependentes dos profissionais de saúde, particularmente dos enfermeiros e médicos e estabelecem com eles, quase sempre uma relação de grande proximidade. Mas nem sempre é assim e nem sempre os profissionais de saúde agem da melhor forma.

“As vezes sinto-me completamente perdida! No hospital pertenço a todos e menos a mim". (Muçulmana, 50 anos)

“Chegam muitos médicos e enfermeiros. O meu corpo é o mapa onde eles se orientam"(Hindu, 45 anos)

“Fazem-me muitas perguntas a que eu não posso responder, não é porque não saiba é porque é à frente de toda a gente... até dos outros doentes". (Muçulmana, 19 anos)

O ambiente hospitalar raramente é agradável pois é muito impessoal. Este fato é determinante para que, fora do seu contexto familiar as pessoas doentes, se sintam desajustadas. Um ambiente mais 'humano' e "harmonioso" em que se possam juntar competências de vária índole - técnicas e instrumentais, culturais e psicológicas, pode fazer a diferença e competência nos cuidados .

"Detesto estar deitada ao pé de pessoas que não conheço. Não gosto de fazer coisas que na minha casa faço sozinha. Está toda a gente a ver". (Hindu, 40 anos)

“Parece que estou em exposição. Nem me importo muito porque eles têm que me tratar mas... levam muito tempo" (Hindu, 25 anos) 
Os ambientes pessoais que conduzem ao bem estar são seguros, confortáveis e funcionais. Permitem desfrutar a natureza e a beleza e oferecem a oportunidade de dar e receber afeto. Muitas pessoas, especialmente aquelas que passam muito tempo em meio hospitalar só muito dificilmente terão o ambiente pessoal que contemple essas necessidades. Devemos envidar esforços para que, mesmo no hospital, as pessoas possam ter algum bem-estar e satisfação. É um direito irrefutável.

No hospital, a especificidade do tratamento a que precisam ser submetidos alguns pacientes cria, muitas vezes, situações de constrangimento e de grande dependência em relação à equipe de saúde. Deitado na cama hospitalar (a quase um metro do chão) por vários dias, a situação que o doente experimenta é a de fragmentação do tempo e das atividades. (SANT'ANNA, 2000)

A própria concepção do que significa corpo, sexualidade, sensualidade, doença, saúde, nojo e prazer, numa sociedade complexa, varia em função da inserção social da pessoa naquele contexto. Quando os profissionais de saúde trabalham com uma série de representações sobre a naturalidade dos corpos, da sensualidade, da sexualidade, dos sentimentos em relação à saúde e à doença, contribui para a difusão e perpetuação de uma série de preconceitos nos grupos sociais. Acabam, por vezes, agindo de maneira inadequada e injusta, reproduzindo desigualdades de género no contexto profissional.(HEILBORN, 2002)

Qualquer que seja o conhecimento que um indivíduo tem de si próprio, não significa que esteja imunizado contra a angústia que lhe é transmitida pela pessoa doente mas, se conhecer as suas necessidades e os seus limites, será capaz de a reconhecer e tomar as medidas necessárias a fim de conservar o seu equilíbrio e o da pessoa que Ihe foi confiada para cuidar.

A hospitalização cria incerteza, desconfiança e um grande medo do desconhecido. Cada exame que se faz, cada médico que pergunta, cada enfermeiro que vem com um tratamento, assusta. Depois há todo um ambiente, limpo, estéril, branco e silenciado, somente quebrado por algum gemido ou choro mais forte de alguém. A noite é difícil, longa e escura e parece durar mais do que em casa. É um período em que não se vive, ou melhor, vive-se de forma silenciosa, amputada e sofredora.

\section{A Privacidade do Corpo}

Quando cuida, o profissional de saúde, é quem mais se aproxima do doente tocando-o, expondo o seu corpo e invadindo o seu espaço. Tudo isso se compreende num contexto de cuidados mas mesmo assim, algumas atividades não necessitariam de tanta exposição e invasão do corpo. A ansiedade, a vergonha e o desconforto que estes procedimentos geram no doente em nada contribuem para o seu restabelecimento e redução da dor e, muitas vezes, dificultam o trabalho do profissional de saúde.

“Às vezes põem-se todos à minha volta e até me falta o ar. É tudo muito pequeno aqui e estamos todos uns em cima dos outros. Não há espaço. (Muçulmana, 50 anos)

As atividades relacionadas com o cuidado propiciam uma interação que se torna cada vez mais impessoal, breve e formal como consequência da realização de rotinas cada vez mais mecanizadas. Há horas para começar e acabar qualquer procedimento. É certo que estes aspectos institucionais são compreensíveis em algumas situações. Noutras são absolutamente inadequadas. O grande problema é que toda a unidade funciona assim: com base no custo/cuidado/tempo.

As questões relacionadas com a privacidade são inúmeras vezes referidas nas disciplinas relacionadas com os cuidados de saúde. Têm normalmente como objetivo chamar a atenção e provocar alguma reflexão sobre posturas e condutas que demonstrem preocupação com a intimidade e a individualidade da pessoa doente respeitando os seus aspectos pessoais e necessidades.

Às vezes não têm cuidado nenhum. Deixam tudo aberto. Ainda ontem tive que ver darem banho a uma senhora idosa da cama ao lado. Ela também não gostou nada de ser observada por mim. (Hindu, 50 anos)

Respeitar a privacidade está entre os principais indicadores de qualidade no atendimento nas instituições de saúde. Um estudo realizado em 2007 revelou que permitir privacidade está intimamente relacionado com a satisfação dos pacientes independentemente da unidade em que se encontrem e há uma forte correlação entre a diminuição do stress e a promoção de serenidade para aceitar o prognóstico (NAYAR, 2005; ADHAJANI, 2008) 
No outro dia, à hora da visita médica, sentaram-se 3 na minha cama porque não havia espaço. O que é que eu podia dizer? (Muçulmana, 19 anos)

A Privacidade é um conceito abstrato, culturalmente definido e dependente da situação. As normas de privacidade definidas pela cultura dominante são redefinidas na relação profissional/cuidado entre o profissional de saúde e o paciente (APPLEGATE; MORSE, 1994).

Por ser tão abstrato, este conceito, implica um conhecimento profundo sobre a natureza física, cultural, espiritual, social e emocional do indivíduo, com personalidade própria e direito à sua dignidade. É importante relembrar que o paciente possui o direito a um atendimento humano, atencioso e respeitoso, por parte de todos os profissionais de saúde. Tem o direito a um local digno e adequado para o seu atendimento. o direito a manter a sua privacidade para satisfazer suas necessidades fisiológicas, inclusive alimentação e higiénicas, quer quando atendido no leito, no ambiente onde está internado ou aguardando atendimento (WALDOW, 2001).

Estudos realizados por MAIRIS, 1994; HADDOCK, 1996; MATITI e SHARMAN, 1999, ajudaram a identificar alguns fatores considerados com precursores da privacidade, tais como manter a dignidade, respeitar e permitir ao doente ter algum controle sobre a sua situação. ENES, 2003; MATITI e TROREY, 2004, referiram que em situação de internamento os pacientes ajustam as suas percepções sobre o que é necessário fazer até passarem aquele mau momento. Uma ênfase especial é dada ao fato deste ajustamento depender do grau de exposição que o seu corpo sofrerá durante os procedimentos técnicos ou a discussão pública que se fará da sua situação de saúde e que eles estão preparados para tolerar.

Ao ser admitido num hospital o doente está implicitamente a dar consentimento para determinadas perdas no que se relaciona com o seu direito à privacidade mas tal não inclui um acesso ilimitado ao seu corpo e nem todas as culturas admitem tamanha invasão. É necessário criar um clima de confiança e merecer essa mesma confiança. Como profissionais de saúde sabemos que o sigilo é uma das pedras angulares para uma prática ética e nunca deveremos perder a noção de que ao invadir a privacidade de uma forma agressiva só porque o que temos que fazer assim obriga, não estamos a respeitar a dignidade da pessoa que se entrega aos nossos cuidados. Na verdade, cuidar é muito mais que um ato, é uma atitude de ocupação, preocupação, de empatia, de responsabilização e de envolvimento afetivo com o Outro exigindo um compromisso dos profissionais de saúde para com o semelhante que exige atenção e cuidados.

\section{Conclusão}

O melhor conhecimento das culturas vai permitir-nos cuidar melhor destas pessoas e compreender de forma mais global os seus universos. É de interesse destacar que verificamos que, apesar de conceitos e formas de viver diferentes, no seu dia-a-dia, estas duas culturas de cunho marcadamente religioso, encaram, quando doentes, os aspectos relacionados às representações e vivências do corpo na doença da mesma forma. De uma maneira geral podemos afirmar que as preocupações são muito semelhantes.

Tanto o Hinduísmo como o Islamismo reconhecem que, Deus tem o conhecimento e o poder de executar e fazer cumprir a Sua vontade, por isso, todo o universo se move segundo o seu desígnio. Deus é generoso o suficiente para dotar os seres humanos com livre arbítrio, para que se tornem responsáveis não só pelas suas ações como pelas escolhas que fazem.

No Hinduísmo há uma crença de que Deus é o Ser Supremo e que toda a criação é o seu corpo. O Islão acredita que os fiéis de Deus são como um corpo que compartilha as mesmas experiências quando manifestam o seu amor, misericórdia e bondade para com os seus semelhantes.

Ambas as culturas acreditam na responsabilidade moral de cada indivíduo para com os outros e na prática das virtudes como a caridade, fazer o bem, justiça, perdão, a moderação no comer e beber, tolerância, misericórdia ou compaixão, auto-controle, fraternidade, amizade, paciência e gratidão.

O Hinduísmo acredita na lei do karma. O Islão acredita na recompensa de Deus para as boas ações e o castigo para os maus atos.

O Hinduísmo é uma religião tolerante. Os hindus acreditam que cada indivíduo tem a opção de seguir um caminho de acordo com a sua inclinação interior e as crenças religiosas. No hinduísmo busca da Verdade é muito mais importante do que a crença ou descrença em Deus ou uma divindade específica. 
O Islão reconhece as religiões que estejam especificamente mencionados no Alcorão mas, os muçulmanos respeitam todos aqueles que acreditam em Deus e que são piedosos independentemente da religião a que pertencem.

O Islão não reconhece qualquer intermediário entre o Homem e Deus. No hinduísmo uma pessoa pode adorar Deus direta ou indiretamente através de um sacerdote ou de um guru.

O Islão acredita na ressurreição e no dia do Juízo Final. O hinduísmo considera a vida no céu e no inferno como temporária.

Os hindus consideram o mundo em que vivemos ilusório e irreal. Não temos a certeza se o que vimos é realidade porque os sentidos são tão imperfeitos que se tornam instrumentos pouco fiáveis. Para o Islão a palavra na terra é tão verdade como no céu ou no inferno.

O hinduísmo não vê grande diferença entre o Homem e o resto dos seres. No Islão há uma distinção clara entre seres humanos e animais. Somente o Homem pode ser um verdadeiro e fiel seguidor de Deus

O Islão prescreve um código de vestuário específico para os muçulmanos com base no princípio de modéstia e do recato. As mulheres devem andar cobertas - embora possam utilizar ou não lenço não devem ter partes do corpo expostas (braço e pernas) em público. No Hinduísmo não há código de vestuário específico, quer para homens ou mulheres excepto em ocasiões específicas ou para executar certos rituais. As mulheres viúvas não podem usar cores fortes nem enfeites mas de uma maneira geral a mulher indiana pode vestir-se de maneira muito feminina e usar muitos adornos.

Obscenidade e nudez em público não são toleradas em nenhuma das culturas.

Tanto o Hinduísmo como o Islamismo não aprovam a convivência e a mistura de sexos antes do casamento. O beijo em público é tabu. O casamento é uma união estabelecida através de consentimento mútuo tendo Deus como testemunha. Sexo pré marital e relações extra conjugais são proibidos nas duas culturas.

Ambas as religiões prescrevem um código de conduta em relação a alimentos e bebidas. Para os hindus, a vaca e o touro são sagrados e não devem ser abatidos. Estão, por isso, proibidos de comer a sua carne. De uma maneira geral a sua alimentação é vegetariana embora alguns comam carne de galinha ou borrego. Para os muçulmanos o porco é um animal impuro. Assim, carne de porco é proibida. Os muçulmanos não podem comer carne a menos que seja preparada de acordo com normas islâmicas ou seja, os animais têm que ser abatidos segundo um ritual muçulmano em talhos especialmente designados para o efeito. Designa-se como carne Hallal. Ambas as culturas proíbem bebidas alcoólicas e substâncias entorpecentes.

Relativamente aos aspectos que se prendem com as representações e vivências do corpo doente gostaríamos de realçar que o corpo na doença é encarado por ambas as culturas como um aspecto perturbador e difícil de gerir.

Os aspectos que mais sobressaem, para ambas as culturas, relativamente às representações do corpo doente relacionam-se com a alteração da própria concepção e imagem do corpo.

Os segmentos de texto mais significativos, imanentes das áreas temáticas e categorias que definimos são, neste artigo, relacionadas com a Vida do Corpo Doente.

Embora tenhamos apresentado outras categorias, gostariamos de referir que o maior numero de asserções se relacionam com o Corpo Público em que os aspectos relacionados com o respeito são quase esquecidos em detrimento de uma técnica ou administração de um medicamento, fazendo com que os profissionais de saúde pelo fato de serem autorizados a intervir nos corpos, esqueçam a sua individualidade, a modéstia e privacidade a que qualquer pessoa tem direito. No que diz respeito à categoria Corpo Desobediente, salientamos que além de doente e dorido, o corpo não obedece e isso dá à pessoa a verdadeira dimensão da sua dependência. Aos profissionais de saúde, restará alguma iniciativa e empatia para lidar com esta situação. Nem sempre é fácil procurar constantemente no outro aquilo que é único e com toda aquela unicidade, produzir novas visões do problema e novas soluções também. Ajudar a pessoa a ultrapassar essa fase de dependência e aprender a lidar com o que fica, ainda que pouco, é um dos maiores desafios para os profissionais de saúde. Nem sempre se consegue mas é muito compensador para o profissional quando se ultrapassa.

O processo de hospitalização gera inúmeras mudanças e rupturas nas relações e no quotidiano. Entrando e saindo do hospital com alguma regularidade faz com que as pessoas doentes aceitem e dependam de rotinas que estão fortemente contra as suas práticas. As horas das refeições, os 
hábitos alimentares, os hábitos de higiene e essencialmente os hábitos relacionados com o não cumprimento dos rituais, têm nestas duas culturas um impacto extremamente negativo e causador de grande angústia e ansiedade.

A Privacidade é encarada como um direito que não se compadece com a invasão do corpo quando esta não é necessária. Aqui reside o problema levantado pelas rotinas hospitalares. A prática rotineira predomina e os profissionais de saúde raramente param para pensar se seria necessária tanta invasão. A ansiedade, a vergonha e o desconforto gerados pela invasão da privacidade, em nada contribuem para o restabelecimento do doente. A pessoa doente vive inúmeros sentimentos contraditórios; por um lado tem que permitir que Ihe toquem ou the mexam no corpo e, por outro, consideram desagradável e desconfortável não só o manuseamento a nível físico como o fato de ter que contar certos pormenores muito privados e até secretos da sua vida. Temos, enquanto profissionais de saúde ter uma atitude de contenção que nos impeça de dizer ou fazer qualquer coisa passível de ofender o código moral ou social daquela pessoa que está face a nós. Para isso precisamos de conhecer profundamente o que a perturba, de modo a não aumentar o sofrimento.

É necessário desenvolver o conhecimento e a pesquisa sobre estas questões de forma a construirmos áreas de competência profissional que nos permitam fazer face e compreender melhor as necessidades dos usuários/doentes de outras culturas. É fundamental que as escolas e as universidades que preparam profissionais de saúde, incluem nos seus Curricula estes conteúdos.

Promover uma comunicação culturalmente competente é, em nosso entender, um passo fundamental para que os planos de saúde tanto a nível regional como nacional, independentemente dos contextos em que se praticam, sejam competentes e eficazes. Uma comunicação assente num conhecimento multicultural, que respeite profundamente os que sofrem e necessitam de cuidados de saúde, certamente contribuirá para um maior sucesso e satisfação no atendimento e na redução das disparidades e reclamações que se verificam hoje em dia nas nossas unidades de saúde, assim como, para um cuidado culturalmente competente.

\section{Referências bibliográficas}

ALBUQUERQUE, L., Imagem corporal em indivíduos amputados. Buenos Aires, Revista Digital, Ano 14, no 131, Abril. 2009

APPLETON, C., The art of nursing, the experience of patients and nurses. Journal of Advanced Nursing, 18, $892-899,1993$

ARIAS, G. et all, En torno del concepto de identidad nacional. Cúcuta, Perspectivas, 1998

AUGÉ, Marc. Não-lugares: introdução a uma antropologia da supermodernidade. Campinas: Papirus, 1994

BAUDRILLARD, J., A sociedade de consumo. Rio de Janeiro, Elfos Editora, 1995

COSTA, J., Percurso, In: Revista de Psicanálise, ano XIII, n 24, 2004

DRUCKER, J., C., Communication in the nursing context. Norwalk, Appleton and Lange, 1990

ELIAS, N., O processo civilizador; uma história dos costumes. Rio de Janeiro, J. Zahar, 2000.

ENES, S., An exploration of dignity in palliative care. Palliative Medicine 17 (3), 263-269, 2003

GARCIA, J., Disease and Culture . Toronto, Ed. Lippincot, 1995

GIDDENS, A., Sociologia. Lisboa, Fundação Calouste Gulbenkian, 2000

GOELLNER, S.V. Corpo, Gênero e Sexualidade: um debate contemporâneo na educação. Petrópolis: Vozes, 2003.

GOFFMAN,E. Estigma: notas sobre a manipulação da identidade deteriorada. Rio de Janeiro, Guanabara, 1988

HADDOCK, J., Towards further clarification of the concept 'dignity'. Journal of Advanced Nursing 24 (5), 924-931, 1996

HARVEY, D., Condição pós-moderna: uma pesquisa sobre as origens da mudança cultural. São Paulo, Ed. Loyola, 2003

HEILBORN, M. L., "Fronteiras simbólicas: género, corpo e sexualidade". Cadernos Sépia no 5. Rio de 
Janeiro, Gráfica JB, 2002

HERZLICH C., PIERRET J., Une maladie dans l'espace public: le sida dans six quotidiens français. Annales, Économies, Sociétés, Civilisations, , .109-1.134, 1988

Le BRETON, D., Antropologia del cuerpo y modernidad. Buenos Aires, Nueva Vision, 1995

MAIRIS, E., Concept clarification in professional practice- dignity, Journal of Advanced Nursing 19(5), 947-953, 1994

MAROY, C. - A análise qualitativa das entrevistas, In: ALBARELLO, L. [et al.] - Práticas e métodos de investigação em ciências sociais. Lisboa, Gradiva, 1997

MATITI, M.R., SHARMAN, J., Dignity: a study of preoperative Patients,Nursing Standard 14 (13), 3235. 1999

MAUSS, M., L'expression obligatoire des sentiments. In: MAUSS, Marcel (org). Essais de sociologie. Paris, Minuit, 1968

MAUSS, M., Les techniques du corps . In : Sociologie et anthropologie . Paris, PUF, 1974

MAYOL, P et al, A invenção do quotidiano. São Paulo, editora Vozes, 2003

MOSCOVICI, S, Dés representations collectives aux representations sociales: elements pour une histoire. Paris, PUF, 1989

NAVARRO, G., El cuerpo y la Mirada. Barcelona , Antropos, 2002

NAYAR, S. , Understanding western and hindu women's identities: A basis for culturally safe practice. New England Journal of Occupational Therapy, 52(1), 38-44, 2005

POLAK, Y. N. S. A corporeidade como resgate do humano na enfermagem. 1996, 131 p., Florianópolis Tese de Doutoramento em Filosofia da Enfermagem), Escola de Enfermagem, Universidade Federal de Santa Catarina

RAMOS, N., Maternage en milieu portugais autochtone et immigré. De la tradition à la modernité. Une étude ethnopsychologique. Tese de Doutoramento em Psicologia. Paris V : Université René Descartes, Sorbonne, 2 vol. 1993

RAMOS, N., Interculturalité, Communication et éducation. Bucareste : Milena Press., 2003

RAMOS, N., Psicologia Clínica e da Saúde. Lisboa, Universidade Aberta, 2004

RAMOS, N., (org.), Saúde, migração e interculturalidade. João Pessoa, EDUFPB, 2008

RAMOS, N., Saúde, migração e direitos humanos. Mudanças - Psicologia da Saúde , 17 (1), Jan-Jun, $1-11 p, 2009$

ROBERTSON, R, Globalization: sociology and cross-disciplinarity. London, Sage, 2000

ROGERS, C., Psychothèrapie et relations humaines, 5a Ed. Paris, 1972

SANT'ANNA, D., Cultos e enigmas do corpo na história, In: STRAY, M., CABEDA, S., Corpos e subjectividades em exercício interdisciplinar. Porto Alegre, EDIPURSE, 2004

SCHILDER, P., A imagem do corpo. Buenos Aires, Paidós, 1999

SHATTUCK, C., Hinduism. London, Routledge, 2009

WALDOW, V. R., Peculiaridades e contradições do cuidar: um estudo etnográfico. Nursing , v.33, ano 4, fev., p. 18-24, 2001

WATSON, J.; CHINN, Peggy L., Art and aesthetics in Nursing. New York, National League for Nursing Press, 1994 